\title{
On the Value of Competition in Procurement Auctions ${ }^{\alpha}$
}

\author{
Olivier Compteyand P hilippe J ehiel ${ }^{z}$ \\ First draft J une 1998 \\ This version: December 1999
}

\begin{abstract}
A bstract
It is commonly stated that ascending price or second price auctions allocate goods e \pm ciently, to those who value them most. This implies that the more bidd ers at the auction stage the more e \pm cient the ${ }^{-}$nal al location. We review this statement when bidders have private information both on a private element and a common element. While the " nal allocation need not be ex post e \pm cient, we show that when bidders are ex ante symmetric, more competition at the auction yields higher e \pm ciency on expectation. When bidders are ex ante asymmetric - in particular with respect to the information on the common element - the statement need no longer be true.
\end{abstract}

Key words: auctions, a \pm liated value, asymmetries, competition, e \pm ciency.

\section{Introduction}

Conventional wisdom suggests that competition is always good to promote e \pm ciency in ascending price or sealed-bid second-price auctions. The best known theory due

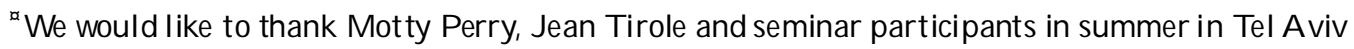
(1998), G erzensee ESSET meeting (1998), Toulouse IDEI, and Paris (Roy) for helpful comments.

${ }^{y}$ C.E.R.A.S.-E .N.P.C., C.N.R.S. (URA 2036), 28 rue des Saints-P pres 75007 Paris France. e-mail: compte@enpc.fr

${ }^{z}$ C.E.R.A.S.-E .N.P.C., C.N.R.S. (UR A 2036), 28 rue des Saints-P pres 75007 Paris France. e-mail: jehiel @enpc.fr and U niversity College London, e-mail: p.jehiel@ucl.ac.uk.
} 
to Vickrey that supports this conclusion is based on the private value paradigm in which (there is one object for sale and) the private information held by every bidder bears solely on his/ her own valuation of the object for sale. Then ascending price or second price auctions all ocate the good e \pm ciently: that is, to the bidder who values it most. Thus, the more participants at the auction stage, the more e \pm cient the ${ }^{-}$nal allocation, which means that competition at the auction stage is good for e \pm ciency. Remarkably, in the private value paradigm, this conclusion holds true whatever the informational structure of the bidders, in particular, whether bidders are ex ante symmetric or not.

Since the pioneering work of Vickrey, the auction paradigm has been extended to cover situations in which the private information held by a bidder a Rects the valuation of every bidder, the so-called a \pm liated value paradigm (see in particular Milgrom and Weber 1982). We note that relatively little attention has been paid to the issue of e \pm ciency of (standard) auctions in such a setup. ${ }^{1}$ Besides, most of the literature on a $\mathrm{a}$ liated value auctions assumes that the private information held by bidders is one-dimensional and that bidders are ex ante symmetric. ${ }^{2}$

In this paper, we wish to analyze the value of competition in ascending or second price auctions when bidders may have multi-dimensional private information and bidders may or may not be ex ante symmetric. This question is of practical importance, since it may help assess whether government agencies should systematically favor the participation of the maximum number of bidders at the auction stage or whether (and how) they should be more selective in the pre-quali ${ }^{-}$cation procedure.

Our interest in multidimensional private information lies in the fact that, in many applied contexts, auctions have features both of the private and of the common (or

\footnotetext{
${ }^{1}$ Some recent papers analyze the extent to which Vickrey-Clarke-Groves mechanisms can be extended in such a setup (see D asgupta-M askin 1999, J ehi el-Moldovanu 1999, A usubel 1999, PerryReny 1999b).

${ }^{2}$ For the dimensionality part, exceptions include Pesendorfer-Swinkels and J ehiel-Moldovanu 1999. For the symmetry part, exceptions include Maskin-Riley (1999), Bulow-K lemperer (1998) and Perry-R eny (1999a).
} 
a \pm liated) value paradigm. Insofar as the private information held on the private and the common element are not related in a deterministic way, the multidimensional setup is more appropriate. For illustrative purpose, consider the case of procurement auctions. Bidders have in general private information on their own cost structure, which is the private value element. They may also have some private information about the general conditions of the task (like the quality of the grounds on which the highway must be built or the shape of the demand when the task includes the provision of services), which is the common value element. We believe that in many situations, these various pieces of information concern very di Rerent aspects of the activity of the bidding ${ }^{-} \mathrm{rm}$, and are not in general related in a speci- $\mathrm{c}$ way.

Our interest in ex ante asymmetries among bidders lies in the fact that, in many applied contexts, bidders are not all (ex ante) similar. One important such asymmetry in procurement auctions is between incumbents and entrants. In this case, asymmetry is likely to bear on the informational structure: Incumbents are presumably better informed about the common value element. ${ }^{3}$ Other asymmetries may concern technological aspects: Bidding - rms may vary with respect to their choice of technology; For those - rms using the same technology (a subset of all bidders), the cost structure is likely to share some common value element.

We consider a model that allows both for asymmetries among bidders and for multidimensional private signals. The general setup that we consider is as follows. There is one object for sale. Each bidder i's valuation is a Rected both by a private element $\mu_{i}$ and a vector of common characteristics $w$. Bidders may be a rected differently by the common value characteristics (to account for potential technological asymmetries, as explained above). Furthermore, each bidder $\mathrm{i}$ is assumed to know his private value element $\mu_{i}$ and some subset of characteristics (relevant to his payo ${ }^{\circledR}$ ) of the common element $w$.

\footnotetext{
${ }^{3}$ We abstract here from market structure considerations, which are clearly al so rel evant in the discussion about incumb ents/ entrants (these are analyzed in the context of auctions with external ities, see J ehiel-M oldovanu 1996 and 1999).
} 
We analyze second price and ascending price auctions in such a setup assuming that bidders are risk-neutral, that the information structure is common knowledge among all bidders, and that all bidders know who is present at the auction stage In particular, when comparing the equilibrium outcome of the auction with or without a given bidder, we take into account the possible change of bidding strategy of the remaining bidders as a response to the change of information (about who is present at the auction stage).

A preliminary insight is the following. In both the second price and the ascending price auctions, as long as the private information held by bidders is multidimensional, ${ }^{4}$ there are always realizations of signal s such that the " nal outcome would have been more e \pm cient if the winner of the auction had not participated in the auction. So from an ex post viewpoint it is not the case that more bidders at the auction stage necessarily results in more (ex post) etcient - nal outcomes. This result holds true whether bidders are ex ante symmetric or not. It is a consequence of the observation that in all mechanisms, the ${ }^{-}$nal allocation must be ex post ine \pm cient with positive probability whenever bidders have multidimensional signals. ${ }^{5}$

The main insights of the paper concern the eßect on expected e \pm ciency of having one more bidder at the auction stage (that is, it concerns the eßect of competition at the auction stage on e \pm ciency). Our ${ }^{-}$rst result concerns the symmetric case. For a reasonably wide class of symmetric settings, we show that in either second price or ascending price auctions, the presence of an extra bidder is always good for e \pm ciency in expectation.

We next explore the erect of having one more bidder in asymmetric cases. Our main insight is that both in second price and in ascending price auctions there are

\footnotetext{
${ }^{4}$ It is su \pm cient that one bidder has a two-dimensional signal and that the distribution of this two-dimensional signal be independent from the private information of other bidders.

${ }^{5}$ In a context where bidders have more dimensions of information than there are alternatives (like in the one object - externality free - auction analyzed in our paper), such a claim is discussed in Maskin (1992). Such a claim turns out to be much more general, and holds even if bidders have fewer signals than there are relevant alternatives to them (see J ehiel and Moldovanu 1999).
} 
situations in which expected e \pm ciency is lower when one more bidder participates in the auction. ${ }^{6}$ In such contexts, more competition at the auction stage deteriorates expected e \pm ciency.

The situations with this property analyzed in this paper all share the feature that the additional bidder has some extra information that is relevant to other bidders and that these other bidders do not have. When the additional bidder has no such information (that is relevant to other bidders), we show (for a wide class of situations) that both in ascending priceand in second price auctions, expected e \pm ciency is higher when this extra bidder participates at the auction.

The situations we identify illustrate two di Berent sources of (expected) ine \pm ciency according to whether second price or ascending price auctions are considered.

In the second price auction situations we anal yze, the presence of the extra bidder is ine \pm cient because the extra bidder gets too often the object whil ethe other bidders are potentially more e \pm cient.

The intuition for this result is as follows. The additional bidder (an incumbent) is informed about a common element that the other bidders (who are least two) do not know (they are entrants, say). When the incumbent bidder is not present, the entrant bidders take the common value element to be equal to its expected value, and the more et cient entrant bidder gets the object. When the incumbent bidder is in, he gets the object - even if the entrant bidders are more e \pm cient than him whenever the realization of the common element is su \pm ciently high. This holds true despite the fact that entrant bidders adjust their bidding strategy to the presence of the incumbent bidder: In order to avoid the incumbent bidder getting the object for high realizations of the common element, the entrant bidders would have to bid very high so that (because they are least two) they would end up paying a high price

\footnotetext{
${ }^{6}$ T his result would also hold true in - rst price auctions. However, it is less surprising, since even in the private value paradigm with onedimensional private signals, one could generate such examples (this is a standard argument against the use of ${ }^{-}$rst price auctions). What our paper shows is that even second price or ascending price auctions may have this feature in a broader setup.
} 
even for low realizations of the common value element, thus resulting in expected losses for entrant bidders; this cannot hold in equilibrium.

In ascending price auctions, we identify another source of (expected) ine \pm ciency. Here the mere presence of the additional bidder modi ${ }^{-}$es the course of competition between the remaining bidders even though (in the basic example) this additional bidder never acquires the object. The point is that the price at which the extra bidder drops out conveys a di ßerent information to the remaining bidders (because some of them share some information with the dropping bidder that the others do not have), and the induced competition between the remaining bidders is then biased in a way that can be detrimental to expected et ciency, as we show.

In Section 2 we describe the model. In Section 3 we analyze the value of compe tition in second price and ascending price auctions. We ${ }^{-}$rst derive a positive result for the symmetric case. We next explore the asymmetric case. Concluding remarks are gathered in Section 4.

\section{The model}

Payo ${ }^{\circledR}$ structure: There is one object for sale. We consider $\mathrm{n}$ potential bidders i $2 \mathrm{~N}=\mathrm{f} 1 ;$;:; ng: W hen a bidder does not get the object, he gets a payo®normalized to zero.

The value of the object to bidder $i$ is assumed to depend on a private element $\mu$ and on a vector of $K$ characteristics $w=\left(w^{1} ; \ldots ; w^{K}\right)$ of the object for sale ${ }^{7}$ This value is denoted $v_{i}(\mu ; w)$.

In order to illustrate the main results of our paper, we will sometimes analyze more speci ${ }^{-} \mathrm{c}$ formulation of the preferences of the bidders. Here are two examples Example 1 (Additive preferences; w purely common) For each bidder i :

$$
v_{i}(\mu ; w)=\mu+{ }_{k 2 k}^{x} w^{k}:
$$

\footnotetext{
${ }^{7}$ With some abuse of notation, $\mathrm{K}$ will sometimes al so denote the set of all characteristics $\mathrm{k}$.
} 
Example 2 (Additive preferences; w partially common) For each bidder $\mathrm{i}$, there exists a subset of characteristics $\mathrm{K}_{\mathrm{i}}$ such that:

$$
v_{i}(\mu ; w)=\mu+{ }_{k 2 K_{i}}^{x} w^{k}:
$$

The interpretation of Example 2 may be as follows. Given the technology used by bidder $\mathrm{i}$, only a subset of characteristics $\mathrm{K}_{\mathrm{i}}$ are relevant to his assessment of the value of the object.

Information structure: Each bidder $\mathrm{i}$ knows his private element $\mu_{i}$, and has some private (partial) information on $w$. The set of variables $\mu_{i} ; w^{k}, i 2 N, k 2 k$ are distributed according to a joint density denoted by $f(\phi$. This density is assumed to be common knowledge among all bidders.

We describe bidder i's information about the common characteristics by de ${ }^{-}$ning for each bidder $\mathrm{i}$ the set $\mathrm{H}_{\mathrm{i}} 1 / 2 \mathrm{~K}$ of characteristics of which bidder $\mathrm{i}$ knows the realization. In case $\mathrm{H}_{\mathrm{i}}=$; , bidder will be said to be uninformed. In case $\mathrm{H}_{\mathrm{i}}=\mathrm{K}$, bidder $\mathrm{i}$ will be said to be fully informed. In all other cases, bidder i will be said to be partially informed.

This informational di ßerentiation between bidders seems particularly relevant for the distinction between incumbents and potential entrants in a procurement auction: Incumbent ${ }^{-}$rms are likely to know more of the characteristics of the object for sale than potential entrants do.

Auction formats: The good is to be sold through an auction procedure. We will consider two auction formats: the second price sealed-bid auction and the ascending price auction, and we will mostly focus on equilibria that do not use dominated strategies. $^{8}$

\footnotetext{
${ }^{8}$ Equilibria in dominated strategies al ways exist in this type of auctions (even in the simple private value paradigm). They are in general considered as implausible because they are poorly robust to mistakes in the bidding behavi or of other bidders.
} 
The second price auction is de ned as follows. Each bidder i simultaneously sends $a$ bid $b$ to the seller. The bidder with maximal bid, i.e. $i_{0}=\arg \max b$ gets the good and pays the second highest bid, i.e. $\max _{i \in i_{0}}$ b to the seller. ${ }^{9}$

The ascending price auction is de ned as follows. ${ }^{10}$ The price starts at a low level, say 0 , at which each bidder is present. The price gradually increases. Each bidder may decide to quit at every moment. When a bidder quits, this is commonly observed by every bidder. The auction stops when there is only one bidder left. The object is allocated to that bidder at the current price. A strategy for each bidder speci ${ }^{-}$es a price at which it quits as a function of current public information and private information. ${ }^{11}$

Policy issues: We are interested in whether or not promoting the maximum participation at the auction stage is good for e土ciency. We distinguish ex post e \pm ciency and ex ante etciency.

If the object is allocated to bidder $i$, (ex post) the social value is given by $v_{i}(\mu ; w)$, which thus measures ex post e \pm ciency. ${ }^{12}$ For each auction format, and for any given strategy pro $^{-}$le $3 / 4$ of the bidders, ex ante e \pm ciency will thus be measured by (remember that $i_{0}$ denotes the winner of the auction):

$$
E_{3 / 4}\left[v_{i_{0}}\left(\mu_{0} ; w\right)\right]={ }_{i 2 N}^{X} \operatorname{Prfi}_{0}=i g E_{3 / 4}\left[v_{i}(\mu ; w) j i_{0}=i\right]:
$$

\footnotetext{
${ }^{9}$ If there are several bidders with maximal bids, one of them is selected at random with equal probability to get the good, and pays that bid to the seller.

${ }^{10}$ We present here the continuous time/ price version of the ascending price auction. This raises some technical di \pm culties regarding the de nition of equilibria in undominated strategies. The equilibria we will refer to are thelimitsas " $>0$ tends to 0 of the equilibria in undominated strategies of the corresponding game in which time is discrete and after each round the price increases by the increment ".

${ }^{11}$ In case all the remaining bidders quit at the same date, one of them is selected at random with equal probability to get the object. He then pays the current price.

${ }^{12} \mathrm{E} \pm$ ciency refers here to productive e \pm ciency (since we abstract from market structure considerations).
} 
Although we are primarily interested in expected e \pm ciency, we start with an example that permits us to assess the e Rect of competition on ex post e \pm ciency.

An introductory example: To $^{-} \mathrm{x}$ ideas, consider example 1 with two bidders $i=1 ; 2$ and two characteristics $k=1 ; 2$. A ssume that $H_{1}=f 1 g$ and $H_{2}=f 2 g$, that is, bidders 1 and 2 have private information on di ßerent characteristics of the object.

Given $\mu_{i}, w^{1}$ and $w^{2}$, bidder i's valuation is

$$
v_{i}(\mu ; w)=\mu+w^{1}+w^{2}
$$

The ex post e \pm cient bidder is denoted by $i^{\star}$. We have:

$$
i^{\infty}=\arg \max _{i} v_{i}(\mu ; w)=\arg \max _{i} \mu:
$$

We assume that all the variables $\mu$ and $w^{k}$ are iid (in particular, $\mu$ and $w^{k}$ are drawn from the same distribution). Bidders 1 and 2 are thus symmetric, and we will analyze the symmetric equilibrium (in undominated strategies) of the sealed bid second price auction.

De $e^{-}$ne the bid function:

$$
b\left(\mu ; w^{i}\right)=\mu+w^{i}+E\left[w^{j} j \mu+w^{j}=\mu+w^{i}\right]
$$

or equivalently, since $\mu$ and $w^{j}$ are drawn from the same distribution (hence $E\left[w^{j} j\right.$ $\left.y+w^{j}=x\right]=x=2$ )

$$
b\left(\mu ; w^{i}\right)=3=2\left(\mu i+w^{i}\right):
$$

It is readily veri ${ }^{-}$ed that these bid functions constitute a symmetric equilibrium of the sealed bid second price auction (and of the ascending price auction in which these bids should be interpreted as the prices at which bidders drop out). ${ }^{13}$ It follows that the object is not necessarily allocated to the most e \pm cient bidder (i.e. the bidder with maximal $\mu_{i}$ ). Speci ${ }^{-}$cally, consider the event in which

$$
\mu_{1}, \mu_{2}, \mu_{1}+w^{1} i w^{2}:
$$

\footnotetext{
${ }^{13} \mathrm{~T}$ he two auction formats are equivalent when there are only two bidders.
} 
Then bidder 2 gets the object even though he is not the most e \pm cient bidder. As a matter of fact, it can be shown quite generally that under the assumed informational structure, there is no sale mechanism that allocates the good to the most e \pm cient bidder (i.e. the bidder with maximal $\mu$ ) with probability 1 (see A ppendix).

The observation above implies that the presence of bidder 2 may actually deteriorate ex post et ciency: under the event considered above, and if bidder 2 were absent, bidder 1 would have got the object and the outcome would thus have been more et cient. 14

Of course the presence of bidder 2 does note always deteriorate ex post e \pm ciency. Speci- cally, whenever

$$
\mu_{2}>\mu_{1} \text { and } \mu_{2}, \mu_{1}+w^{1} i w^{2}
$$

the presence of bidder 2 improves e \pm ciency.

Similar observations clearly carry over to the case where there are more than two bidders and for more general distributions of signals, so that we may in general expect both a positive and a negative eRect on e \pm ciency. The rest of the paper addresses how these e Rects aggregate in second price sealed bid auctions and in ascending price auctions. In other words, we wish to analyze whether competition is good or not for e \pm ciency from an ex ante viewpoint. Our analysis will show that whether bidders are symmetric or not plays a key role.

\section{The Symmetric Case}

In this Section we assume that all bidders share the same valuation function $v_{i}$, which we will denote by $\mathrm{V}$ : When all bidders are informed about the same characteristics $\left(\mathrm{H}_{\mathrm{i}}=\mathrm{H}_{\mathrm{j}} 8 \mathrm{i} ; \mathrm{j}\right)$, both the second price auction and the ascending price auction clearly select the most e \pm cient bidder (the bidder with largest $\mu$ ). Thus, the presence of an additional bidder may only increase e \pm ciency.

\footnotetext{
${ }^{14}$ We assume that when there is only one bidder, he gets the good for free, which amounts to having a reserve price set to 0 .
} 
We will now analyze the more interesting case in which bidders are not informed about the same characteristics (so that ex post ine \pm ciencies may arise). We now de ${ }^{-}$ne a relatively broad class of symmetric settings of this sort.

De ${ }^{-}$nition 1 Assume K , N. A setting is said to be symmetric if 1) All bidders have the same valuation function $v_{;} 2$ ) Each bidder $i$ knows $\mu_{i}$ and $w^{i}$, that is, $\left.H_{i}=f i g ~ 8 i ; 3\right)$ The variables $\left(\mu ; w^{i}\right)$ are i.i.d. among bidders and independent from $\mathrm{w}^{k}, \mathrm{k}>\mathrm{N}$ : they are distributed according to $\mathrm{g}(\varnothing$ on $[\underline{\mu} ; \bar{\mu}] f[\mathrm{w} ; \bar{w}] ; 3)$ The valuation function $v$ is separable in each bidder i's information, and symmetric with respect to the other common value charcateristics $k \in i$. That is, there are functions $u\left(\mu ; w^{i}\right)$ and $A\left(w^{k}\right)$ such that:

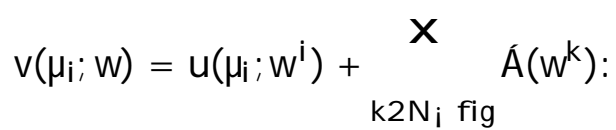

Note that in a symmetric setting as described above, we may de ne

$$
h\left(\mu_{i} ; w^{i}\right)=u\left(\mu ; w^{i}\right) \text { i } \quad \dot{A}\left(w^{i}\right) ;
$$

and bidder $i$ is the most $e \pm$ cient bidder if $h\left(\mu ; w^{i}\right)$ is largest among bidders. The following Proposition establishes that both in the second price and the ascending price auctions (and by restricting attention to symmetric equilibria), expected e \pm ciency increases with the number of bidders.

Proposition 1 Consider the symmetric setting. Suppose that 1$){ }^{\circ} \mathrm{N}(\mathrm{z})=\mathrm{Z}+\left(\mathrm{N}_{\mathrm{i}}\right.$ 1) $E\left[A ́\left(w^{k}\right)\right.$ j $\left.u\left(\mu_{k} ; w^{k}\right) \cdot z\right]+E\left[A ́\left(w^{k}\right)\right.$ j $\left.u\left(\mu_{k} ; w^{k}\right)=z\right]$ is (strictly) increasing in $z$, and 2$){ }^{\prime}(z)=E\left[h\left(\mu ; w^{i}\right) j u\left(\mu ; w^{i}\right)=z\right]$ is a (strictly) increasing function of $z$. Then for any $m$ - $N$, the sealed bid second price auction with $m$ bidders and the ascending auction with $\mathrm{m}$ bidders each has a unique symmetric equilibrium. Furthermore, the aggregate expected e \pm ciency in this equilibrium increases with the number $\mathrm{m}$ of bidders.

The intuition for Proposition 1 is as follows. Consider the second price sealed bid auction. The equilibrium bid of bidder i should aggregate the multidimensional 
private information $\left(\mu ; w^{i}\right)$ held by bidder $i$. The separability of $v(\Phi \Phi$ ensures that each bidder i's equilibrium behavior should be a function of $u\left(\mu ; w^{i}\right)$. Condition 1 of Proposition 1 then ensures that a symmetric equilibrium allocates the good to $\arg \max u\left(\mu ; w^{i}\right)$. Whenever condition 2 holds, the aggregate value $u\left(\mu ; w^{i}\right)$ is a \pm liated with the e \pm ciency criterion as measured by $h\left(\mu ; w^{j}\right)$. More competition at the auction stage is then good for e \pm ciency in expectation.

Proof. It is standard to show that under the three ${ }^{-}$rst conditions a) there exists a unique symmetric equilibrium and b) equilibrium bids are strictly increasing functions of $u\left(\mu ; w^{i}\right) .{ }^{15}$ Given this property, the object is allocated to the bidder with highest $u\left(\mu ; w^{i}\right)$. Net of the common component ${ }_{k 2 N}^{P} A ́\left(w^{k}\right)$, the expected welfare is equal to:

$$
\begin{aligned}
G & =E\left[h\left(\mu_{0} ; w^{i_{0}}\right) j i_{0}=\arg \max _{i} u\left(\mu ; w^{i}\right)\right] \\
& =z E\left[h\left(\mu_{i_{0}} ; w^{j^{0}}\right) j i_{0}=\arg \max _{i} u\left(\mu_{i} ; w^{i}\right) ; u\left(\mu_{0} ; w^{j_{0}}\right)=z\right] h(z) d z ;
\end{aligned}
$$

where $h(z)=i \frac{d}{d z} H(z)$, with

$$
H(z)=\operatorname{Prfmax} u\left(\mu ; w^{i}\right), \quad z g
$$

By symmetry, we have

$E\left[h\left(\mu_{0} ; w^{j^{0}}\right) j j_{0}=\arg \max _{i} u\left(\mu_{i} ; w^{i}\right) ; u\left(\mu_{0} ; w^{j_{0}}\right)=z\right]=E\left[h\left(\mu_{k} ; w^{k}\right) j u\left(\mu_{k} ; w^{k}\right)=z, \max _{j \in k} u\left(\mu ; w^{j}\right)\right] ;$

${ }^{15}$ In a sealed bid second price auction, player i's equilibrium bid satis ${ }^{-}$es:

$$
b_{i}^{\mathrm{a}}\left(\mu_{i} ; w^{\mathrm{i}}\right)=u\left(\mu_{i} ; w^{\mathrm{i}}\right)+{ }_{k \cdot m}^{X} E\left[\dot{A}\left(w_{k}\right) j \max _{j \in i} u\left(\mu_{j} ; w^{j}\right)=u\left(\mu_{i} ; w^{i}\right)\right]+{ }_{k>m}^{X} E\left[A ́\left(w_{k}\right)\right]
$$

which is equal to ${ }^{\circ} m\left(u\left(\mu_{i} ; w^{i}\right)\right)+(N ; m) E\left[A ́\left(w_{k}\right)\right]$ because the pairs $\left(\mu_{j} ; w^{j}\right)$ are iid. Bids thus increases with $\mathrm{u}\left(\mu ; w^{i}\right)$ because ${ }^{\circ}$ is an increasing function.

In an ascending price auction, bids are also increasing function of $z_{i}=u\left(\mu_{i} ; w^{i}\right)$. If $n$ bidders have not dropped out yet, then bidder i's bidding function is equal to (up to an additive constant), ${ }_{n}\left(z_{i}\right)$, which is also increasing in $z_{i}$ if ${ }^{\circ} N$ is. (This follows the standard arguments developed in Milgrom and Weber 1982). 
and because the random variables $\left(\mu ; w_{i}\right)$ are independent from one another, we obtain

$$
G={ }_{z}^{Z} E\left[h\left(\mu_{k} ; w^{k}\right) j u\left(\mu_{k} ; w^{k}\right)=z\right] h(z) d z:
$$

Since $E\left[h\left(\mu_{k} ; w^{k}\right) j u\left(\mu_{k} ; w^{k}\right)\right]={ }^{\prime}(z),(2)$ implies:

$$
G={ }_{z}^{\prime}(z) h(z) d z={ }^{\prime}(\underline{z})+{ }_{z}^{\prime} \rho(z) H(z) d z
$$

Since $q(z), 0$, and since for any $z, H(z)$ increases with the number of bidders, we conclude that welfare increases with the number of bidders.

\section{The Asymmetric Case}

Symmetry plays an important role in Proposition 1 . We now investigate asymmetric settings, and we analyze whether the conclusion that more bidders at the auction stage enhances e \pm ciency is true.

A nalyzing asymmetric settings in auctions is in general very hard because in equilibrium bidding strategies are the result of a sophisticated inference process. B e sides, the addition of one more bidder may completely change this inference process making the comparison very di \pm cult. O ur relatively simple information structure will nevertheless allow us to carry out these comparisons for three broad kinds of informational asymmetries.

Asymmetric setting 1 : 8i $2 \mathrm{f} 1 ;:: ; \mathrm{n}$ i $1 \mathrm{~g}, \mathrm{H}_{\mathrm{i}}=; ; \mathrm{H}_{\mathrm{n}}=\mathrm{K}$.

A symmetric setting $2: \mathrm{K}, 2 ; \mathrm{n}=3 ; \mathrm{H}_{1}=\mathrm{flg} ; \mathrm{H}_{2}=; ; \mathrm{H}_{\mathrm{n}}=\mathrm{K}$.

Asymmetric setting 3 : 8i $2 \mathrm{f} 1 ; \ldots ; ; \mathrm{n} ; \mathrm{lg}, \mathrm{H}_{\mathrm{i}}=\mathrm{K} ; \mathrm{H}_{\mathrm{n}}=$;.

In all three settings, we will be interested in the eßect of allowing bidder $n$ to participate. For simplicity, we will assume throughout this section that all the variable $\mu ; w^{k}$ are independent from one another. 
The three settings di ßer in several respects. The ${ }^{-}$rst di @erence is about the information held by the extra bidder $\mathrm{n}$. In asymmetric settings 1 and 2, the extra bidder is fully informed of the common value element; in asymmetric setting 3 , the extra bidder is totally uninformed of the common value element. Thus, in settings 1 and 2 , the extra bidder may be thought of as an incumbent while in setting 3 he may be thought of as an entrant.

The second di ßerence is about the private information held by bidders other than the extra bidder. In setting 1, these are totally uninformed of the common element (they may thus be thought of as entrants); in setting 3, they are fully informed of the common element (they may thus be thought of as incumbents); in setting 2, they are partially and asymmetrically informed of the common element (bidder 2 knows more of the common element than bidder 1 does).

Our results are as follows. In asymmetric setting 1, we will show that the participation of the extra bidder $n$ may deteriorate (ex ante) e \pm ciency if the object is allocated with a sealed bid second price auction. In contrast, if the object is allocated with an ascending price auction, the participation of the informed bidder may only enhance e \pm ciency.

In asymmetric setting 2, we will show that the comparison between the ascending price auction and the sealed bid second price auction may be reversed: we exhibit conditions under which etciency is lower when the informed bidder participates in the ascending price auction, but not in the sealed bid second price auction.

In asymmetric setting 3, we will show that the participation of bidder $\mathrm{n}$ is positive in both the sealed bid second price auction, and in the ascending auction.

To conclude this short presentation, note that in asymmetric setting 3, the bidding strategy of bidders $\mathrm{i}=1 ;:: \mathrm{n}$ i 1 is una Rected by the presence of the extra bidder $n$. This is because in this setting bidders $\mathrm{i}=1 ;:: \mathrm{n}_{\mathrm{i}}$ l have nothing to infer from bidder $\mathrm{n}$. (This is, of course, not the case in either settings 1 or 2.) Our results thus suggest that it is the bias on equilibrium bids induced by the extra bidder that may invalidate the positive eßect of competition. Furthermore, our analysis of set- 
tings 1 and 2 will highlight two distinct sources of ine \pm ciencies that may arise due to the presence of the extra bidder. We will come back at length to these sources of ine \pm ciencies.

\subsection{A dding an informed bidder to uninformed bidders}

We consider asymmetric setting 1 . To get some intuition, consider ${ }^{-}{ }^{-}$st the simple payo ${ }^{\circledR}$ structure described in Example 1:

$$
v_{i}\left(\mu_{i} ; w\right)=\mu+{ }_{k 2 k}^{x} w^{k} ;
$$

and assume that there are 3 bidders: bidders 1 and 2 are uninformed of $w\left(\mathrm{H}_{1}=\right.$ $\mathrm{H}_{2}=$; ) whereas bidder $\mathrm{n}=3$ is fully informed of $\mathrm{w}\left(\mathrm{H}_{3}=\mathrm{K}\right)$. A lso assume that the informed bidder 3 is always less e \pm cient than the two uninformed bidders $i=1 ; 2$. That is,

$$
\operatorname{Prf} \max _{i<n} \mu>\mu h g=1:
$$

Consider the sealed bid second price auction. When bidder 3 is absent, the equilibrium bid of the uninformed bidder $\mathrm{i}=1 ; 2$ with private element $\mu$ is

$$
\mu+E\left({ }_{k 2 k}^{x} w^{k}\right) \text {. }
$$

Thus, the second price auction allocates the good e \pm ciently, to the bidder with highest $\mu$.

We now show that the presence of bidder 3 must deteriorate e \pm ciency. Suppose (by contradiction) that the presence of bidder 3 does not deteriorate et ciency. Then because of (4) bidder 3 must get the object with probability 0 . So assume that (in equilibrium) bidder 3 never gets the object. Since bidders 1 and 2 choose their bids independently, one of the two uninformed bidders, say bidder 1 , must choose to bid $b_{1}, \stackrel{1}{\mu}_{3}+W$ with probability 1 where $W$ is the largest realization of ${ }_{k 2}^{P}{ }_{k} W^{k}$. Otherwise, maxf $b_{1}$; $b_{2} g$ would be smaller than or equal to some $b<\mu_{B}^{1}+W_{w}$ with positive probability, and bidder 3 would be able to secure positive expected pro ${ }^{-}$ts, contradicting the premise that he does not get the object in equilibrium. 
Now observe that whenever bidder 2 wins, he must pay a price at least equal to $b_{1}$, hence at least equal to $\dot{\mu}_{3}+w$. However, bidder 2's expected value from winning the object is $\mu_{2}+\mathrm{E} w$ (because bidder 3 is supposed not to get the object and because bidder l's bid does not convey any information on $w$ ). When

$$
\mu_{2}+E w_{i}(\stackrel{\mu}{\mu}+w)<0 ;
$$

bidder 2 with private element $\mu_{2}$ will not acquire the object, since otherwise he would make losses. Thus bidder 1 should acquire the object. However, bidder 1 may be less et cient than bidder 2 , since condition (5) does not imply that $\mu_{2}<\mu_{1}$. To summarize, in any event where

$$
\mu_{1}<\mu_{2} \text { and } \mu_{2}+E w<\mu_{B}^{1}+w ;
$$

the object would be allocated to bidder 1 even though he is not the most $\mathrm{e} \pm$ cient bidder. Clearly, since $E w<W$, this event may have positive probability even when condition (3) holds. $\mathrm{E} \pm$ ciency is then deteriorated with positive probability.

The following proposition states more gen erally our result where bidder $\mathrm{n}$ (only) is assumed to know $w$ while bidders $i=1 ; \cdots: n$ i 1 are totally uninformed about $w$ :

Proposition 2 Assume $n, 3$. A ssume the uninformed bidders $i=1 ; \cdots: n$ i 1 have the same valuation function (i.e. $v_{i}(\phi \Phi) v(\phi \Phi)$, and that the distributions of their private value elements $\mu$ have the same full support (i.e. $\mu ; i^{i}=\mu, i j$ ). Also assume that bidder $\mathrm{n}$ is the most $\mathrm{e} \pm$ cient bidder with probability 0 , and that the event ${ }^{16} f E_{\mathbb{R}} \mathrm{V}(\boldsymbol{\mu} ; \boldsymbol{w})<\mathrm{V}_{\mathrm{n}}\left(\mu_{h} ; \boldsymbol{w}\right) \mathrm{g}$ has strictly positive probability. Then the presence of bidder $\mathrm{n}$ deteriorates ex ante e \pm ciency when the object is al located with a second price auction. Besides, in any equilibrium (in undominated strategies) bidder $\mathrm{n}$ gets the object with positive probability.

Proof. For expositional simplicity, we assume that $w$ is onedimensional, and we let $w$ denote the largest realization of $w$. Consider ${ }^{-} r s t$ the case without the informed

\footnotetext{
${ }^{16}$ denotes the random variable $w$; we use this notation here to avoid confusion with the realization $\mathrm{w}$ of this random variable.
} 
bidder $\mathrm{n}$. Then bidder $\mathrm{i}$ with highest value of $\mathrm{E}_{\mathrm{w}} \mathrm{v}(\mu ; \mathrm{w})$ gets the object. Given that the uninformed bid ders have the same valuation function, this bidder is also arg max $\mu$ who is the most e \pm cient uninformed bidder. Given that the informed bidder $\mathrm{n}$ is the most e \pm cient with probability zero, we obtain that the most e \pm cient bidder $\mathrm{i}=1 ;::$ :n gets the object.

Consider now the case with the informed bidder $\mathrm{n}$. Bidder n's dominant strategy is to bid

$$
b_{n}\left(\mu_{n} ; w\right)=v_{n}\left(\mu_{n} ; w\right):
$$

Suppose (by contradiction) that the presence of bidder $n$ does not deteriorate e \pm ciency. Then because bidder $\mathrm{n}$ is less etcient than bidders $\mathrm{i}=1 ;:: \mathrm{n} ; 1$, bidder $\mathrm{n}$ must get the object with probability 0 . Since bidders choose their bids independently, at least one of the bidders $i=1 ;:: n$ i 1 must choose to bid $b, v_{n}\left(\mu_{h}^{1} ; w\right)$ with probability 1 . Suppose for example that $b_{1}>v_{n}\left(\mu_{n}^{1} ; W\right)$ with probability 1 .

Now observe that whenever bidder $\mathrm{i}<\mathrm{n}$, i $\Theta 1$ wins, he must pay a price at least equal to $b_{1}$, hence at least equal to $v_{n}\left(\mu_{h}^{1} ; w\right)$. However, bidder i's expected value from winning the object is $E_{w} V\left(\mu_{i} ; w\right)$ (because bidder $n$ is supposed not to get the object and because bidder 1 's bid does not convey any information on $w)$. When

$$
E_{w}[v(\mu ; w)] ; \quad v_{n}\left(\mu_{h} ; w\right)<0 \text {; }
$$

bidder i with private element $\mu$ will not acquire the object, since otherwise he would make losses. When this condition is met for every uninformed bidder $\mathrm{i}<\mathrm{n}$, i 61 (this event has positive probability by assumption), bidder 1 should acquire the object. However, bidder 1 may be less e \pm cient than bidders $\mathrm{i}<\mathrm{n}, \mathrm{i} \in 1$, since condition (6) does not imply that $\mu<\mu$. To summarize, in any event where for all $\mathrm{i}<\mathrm{n}, \mathrm{i} \in 1$

$$
\mu_{1}<\mu \text { and } E_{w}[v(\mu ; w)]<v_{n}\left(P_{h} ; W\right) \text {; }
$$

the object would be al located to bidder 1 even though he is not the most $\mathrm{e} \pm$ cient bidder. This event has positive probability by assumption, which shows the ine \pm ciency result. 
R egarding equilibria in und ominated strategies, observe ${ }^{-}$rst that bidder $n$ must bid $b_{n}\left(\mu_{h} ; w\right)=v_{n}\left(\mu_{h} ; w\right)$, since he has nothing relevant to infer from the other bids. Suppose now (by contradiction) there is an equilibrium in undominated strategies in which the informed bidder $\mathrm{n}$ never acquires the object. Then bidder $\mathrm{i}$, $\mathrm{i}<\mathrm{n}$, with type $\mu$ must bid $b(\mu)=E_{w}\left[v\left(\mu_{i} ; w\right)\right]$, since the event of winning would convey no information about the value of $w$. However, there are realizations of $\mu_{i} ; \mu_{n} ; w$ such that $\mathrm{E}_{\mathbb{Q}}[\mathrm{V}(\mu ; \boldsymbol{\theta})]<\mathrm{v}_{\mathrm{n}}\left(\mu_{\mathrm{h}} ; \mathrm{w}\right)$ contradicting the premise that bidder $\mathrm{n}$ never acquires the object.

\subsubsection{When there is no competition among uninformed bidders}

The presence of two (or more) uninformed bidders is key to the result of Proposition 2. If there is only one uninformed bidder (i.e. $n=2$ ), the next result shows that the addition of the informed bidder $\mathrm{n}$ always improves e \pm ciency.

Proposition 3 Assume $n=2$. The presence of the extra bidder $n$ always improves expected et ciency.

Proof. Let bidder 1 be the uninformed bidder with private value element $\mu_{1}$. Let bidder 2 be the informed bidder with private value element $\mu_{2}$ and common value element $w$. The joint distribution of $\left(\mu_{2} ; w\right)$ is denoted by $1 / k \phi \emptyset$. We now show that for each realization of $\mu_{1}, \mu_{1}=\mu_{1}^{\alpha}$, there is an expected e \pm ciency gain induced by the presence of the informed bidder. ${ }^{17}$ Given a realization ( $\mu_{2} ; \mathrm{w}$ ), the informed bidder bids $b_{2}\left(\mu_{2} ; w\right)=v_{2}\left(\mu_{2} ; w\right)$ (because he knows everything that is relevant to him). Let $b_{1}$ denote the equilibrium bid of the uninformed bidder ( with type $\mu_{1}^{\natural}$ ). The expected et ciency gain (possibly negative) due to the presence of the informed bidder is

$Z$

$$
\Phi=\underset{b_{2}\left(\mu_{2} ; w\right)>b_{1}}{Z}\left[\left(v_{2}\left(\mu_{2} ; w\right) ; v_{1}\left(\mu_{1}^{\alpha} ; w\right)\right] / / \mu_{i} ; w\right) d \mu_{2} d w ;
$$

\footnotetext{
${ }^{17} \mathrm{~T}$ he expectation bears over $\mu_{2}, \mathrm{w}$.
} 
which can be rewritten as:

$$
\Phi=E_{\mu_{2} ; w}\left[v_{2}\left(\mu_{2} ; w\right) ; v_{1}\left(\mu_{1}^{\alpha} ; w\right)\right]+\underset{b_{2}\left(\mu_{2} ; w\right)<b_{1}}{Z}\left[v_{1}\left(\mu_{1}^{\alpha} ; w\right) ; b_{2}(\mu L ; w)\right]^{1} /\left(k \mu_{2} ; w\right) d \mu_{2} d w ;
$$

(by noting that $b_{2}\left(\mu_{2} ; w\right)=v_{2}\left(\mu_{2} ; w\right)$ ). Finally, observe that $\frac{R}{b_{2}\left(\mu_{2} ; w\right)<b_{1}}\left[v_{1}\left(\mu \frac{\alpha}{\alpha} ; w\right) ;\right.$ $\left.b_{2}\left(\mu_{2} ; w\right)\right]^{1} /\left(\mu_{2} ; w\right) d \mu_{2} d w$ is the equilibrium payo ${ }^{\circledR}$ of the uninformed bidder 1 (with private element $\left.\mu_{1}^{\mathrm{a}}\right)$. This expression is no smaller than $E_{\mu p ; w}\left[v_{1}\left(\mu_{1}^{\alpha} ; w\right) ; v_{2}\left(\mu_{2} ; w\right)\right]$ because the uninformed bidder ( with type $\mu_{i}^{q}$ ) can always submit a very high bid (higher than any conceivable bid of the informed bidder), thus securing an expected payo® of $E_{\mu_{2} ; w}\left[V_{1}\left(\mu_{1}^{\alpha} ; w\right) ; v_{2}(\mu q ; w)\right]$. It follows that $\$, 0$.

Coming back to Proposition 2, we conclude that it is the competition between the uninformed bidders that is key to the deterioration of e \pm ciency when a less $\mathrm{e} \pm$ cient but informed bidder is present.

\subsubsection{When there are many uninformed bidders}

Several results in the literature suggest that some ine \pm ciencies arising when there are few agents may disappear when there are many agents. ${ }^{18}$ We now show that the negative eßect induced by the presence of the informed bidder may continue to hold even when there are many uninformed bidders.

Proposition 4 Let $\mathrm{n}, 3$ bidders have the same valuation function $\mathrm{v}_{\mathrm{i}}(\phi \phi=\mathrm{v}(\phi \Phi$ that is increasing in all arguments. A ssume that the variables $\mu \mathrm{i}=1 ; \ldots ; ; \mathrm{n} i 1$ are identically distributed over $[0 ; 1]$, and that $w$ is distributed over $[w ; \bar{w}] \mu[0 ; 1]$. We let $\mu_{\mathrm{nf}}$ denote the private element of the informed bidder $\mathrm{n}$, which is also distributed on $[0 ; 1]$. Let $\forall(1)=E_{w}[v(1 ; w)]$. De ne $b^{\alpha}=[\forall(1) v(1 ; w)]^{1=2}$ and $\mathbb{B}^{\alpha}=1 ; \quad\left[\frac{\forall(1)}{v(1 ; w)}\right]^{1=2}$. Consider any equilibrium that is symmetric among the uninformed bidders. In such an equilibrium, at the limit where $\mathrm{n}$ is very large, all $\mathrm{n}$ i 1 uni nformed bidders bid

\footnotetext{
${ }^{18}$ See for example, Gul and Postlewaite (1992) and in an auction context Pesendorfer and Swinkels (1999).
} 
below $b^{\alpha}$ with probability at least $\mathbb{R}^{\alpha}$, that is:

$$
\operatorname{Prfmax} \operatorname{li}_{i<n}<b^{\alpha} g, \quad \mathbb{R}^{\alpha}:
$$

Proof. Consider an equilibrium that is symmetric among the uninformed bidders. Consider an uninformed bidder $\mathrm{i}$ with private element $\mu^{\alpha}$ who makes the highest bid (among the uninformed bidders). Let $\mathrm{G}\left(\mu_{\mathrm{q}}^{\mathrm{q}} ; \mathrm{b}\right)$ denote the payo® obtained by such $a$ bidder when he bids $b$ Also let $b^{\left(n_{i} 2\right)}$ the largest equilibrium bid of the $(n ; 2)$ other uninformed bidders. The payo ${ }^{\circ} \mathrm{G}\left(\mu^{\alpha} ; b\right)$ satis $^{-}$es ${ }^{19}$

$$
G\left(\mu^{\alpha} ; b\right) \cdot \operatorname{Pr}\left(v\left(\mu_{n f} ; w\right) \cdot b\right)\left[E\left[v\left(\mu^{\alpha} ; w\right) j v\left(\mu_{n f} ; w\right) \cdot b\right] i \quad E\left[b^{\left(n_{i} 2\right)} j b^{\left(n_{i} 2\right)} \cdot b\right]\right] .
$$

The term $E\left[v\left(\mu_{f}^{\alpha} ; w\right) j v\left(\mu_{n f} ; w\right) \cdot b\right]$ is no larger than $v(1)$ since $v(: ;:)$ is weakly increasing in $\mu^{\alpha}$ and $w$. Besides, for the maximal value of $\left.b, E\left[b^{\left(n_{i} 2\right)} j b^{\left(n_{i} 2\right)} \cdot b\right]\right]=$ $\left.E b^{(n i} 2\right)$.

Since in equilibrium any bidder must be making non negative gains, we obtain:

$$
E b^{(n ; 2)} \cdot \mathbb{v}(1)
$$

$D e^{-}$ne $b^{\alpha}=[\forall(1) v(1 ; W)]^{1=2}$ and $\mathbb{B}=1 ;\left[\frac{\mathbb{W}(1)}{V(1 ; W)}\right]^{1=2}$. The expectation $E b^{\left(n_{i} 2\right)}$ is bounded from below by $b^{\alpha} \operatorname{Pr}\left(b^{\left(n_{i} 2\right)}, b^{\alpha}\right)$, implying that

$$
\operatorname{Prfb}^{\left(n_{i} 2\right)}<b^{\infty} g, \quad \mathbb{R}^{\infty}:
$$

Finally, let $b^{\left(n_{i} 1\right)}$ denote the largest equilibrium bid of the $n_{i} 1$ uninformed bidders. In a symmetric equilibrium,

$$
\operatorname{Prfb}^{\left(n_{i} 1\right)}<b^{\alpha} g=\left[P r f b^{\left(n_{i} 2\right)}<b^{\alpha} g\right]^{\frac{n_{i 1} 1}{n_{i} 2}}
$$

which implies the result at the limit where $\mathrm{n}$ is large.

This result implies that at the limit where the number of uninformed bidders is very large, the addition of an informed bidder may cause an e \pm ciency loss. To see

\footnotetext{
${ }^{19}$ Bidder i obtains a positive payo ${ }^{\circledR}$ only when the informed bidder $\mathrm{n}$ bids bel ow $\mathrm{b}$ The price he then pays is no smaller than $b^{\left(n_{i} 2\right)}$.
} 
this, observe that whenever $v\left(\mu_{n f} ; w\right)>b^{\alpha}$, the informed bidder must get the object with a probability no smaller than ${ }^{*}$. If he had not been present, $\underset{i<n}{\arg \max } \mu$ would have got the object. For $n$ very large, $\underset{i<n}{\arg \max } \mu$ is almost surely very close to 1 . Thus when $\mathrm{n}$ is arbitrarily large the presence of the informed bidder deteriorates et ciency by (at least):

$\mathbb{R}^{\circledR} E\left(v(1 ; w) ; v\left(\mu_{\text {inf }} ; w\right) j v\left(\mu_{\text {inf }} ; w\right)>b^{a}\right) \operatorname{Pr}\left(v\left(\mu_{\text {inf }} ; w\right)>b^{a}\right):$

\subsubsection{Ascending price auction}

We conclude this part by observing that in an ascending price auction (instead of a second price auction), the presence of the informed bidder would not deteriorate et ciency.

Proposition 5 Let bidder $\mathrm{i}=1 ;::: \mathrm{n}_{\mathrm{i}} 1$ with valuation $\mathrm{v}_{\mathrm{i}}(\phi \Phi$ be uninformed (of $\mathrm{w})$. Let bidder $n$ with valuation $v_{n}\left(\phi \varnothing\right.$ be informed of $w$. De ${ }^{-} n e{ }^{\prime} i(\mu ; z)=E\left(v_{i}(\mu ; w) j\right.$ $\left.v_{n}\left(\mu_{h} ; w\right)=z\right)$ and assume that $0<\frac{@{ }^{\prime}}{i}\left(\mu_{i} ; z\right)<1$ for all $\mu$. If the object is al located with the ascending price auction, the presence of bidder $n$ always improves expected et ciency.

Proof. The ascending price auction without the informed bidder $\mathrm{n}$ allocates the good to the most $\mathrm{e} \pm$ cient uninformed bidder. Consider now the ascending price auction with all bidders. The informed bidder $n$ (with private information $\mathrm{h}_{h}, \mathrm{w}$ ) re mains at the auction until the price reaches the level $b_{n}=v_{n}\left(\mu_{h} ; w\right)$ : We next observe that as long as the informed bidder has not dropped out, and whatever the other uninformed bidders have done, an uninformed bidder $\mathrm{i}$ (with private information $\mu_{\mathrm{i}}$ ) remains at the auction until the price reaches the level $\mathrm{b}$ wher $\mathrm{e}^{20}$

$$
b={ }^{\prime}(\mu ; b):
$$

This is because the expected value of the object to bidder i conditional on the actions of others depends solely on the price at which the informed bidder $\mathrm{n}$ drops out (bidder

\footnotetext{
${ }^{20} \mathrm{~T}$ he condition on ${ }^{\prime}(\phi)$ ensures that for each $\mu_{i}$ this $\mathrm{b}$ is uniquely de- ned and increasing in $\mu$.
} 
i has nothing relevant to infer from the price at which the other uninformed bidders drop out).

Once bidder $\mathrm{n}$ has dropped out, bidder $\mathrm{i}$ (if he has not dropped out yet) drops out at

$$
\mathrm{b}={ }^{\prime} \mathrm{i}\left(\mu ; b_{h}\right):
$$

Under each realization $\mu_{1} ;:: ; \mu_{i} 1 ; z\left(=v_{n}\left(\mu_{h} ; w\right)\right)$, the winner of the object is either the uninformed bidder for which ${ }^{i}\left(\mu_{i} ; z\right)$ is largest, or the informed bidder, depending on whether ${ }^{\prime} \mathrm{i}(\mu ; \mathrm{z})$ is larger or smaller than $\mathrm{z}$.

From the de- nition of the functions ' $i$, expected etciency under the event $\mathrm{f} \mu_{1} ;:: ; \mu_{h_{i}}, ; z g$ is

$$
\max _{i} E_{w}\left[v_{i}(\mu ; w) j v_{n}\left(\mu_{n} ; w\right)=z\right]=\max _{i}{ }_{i}(\mu ; z)
$$

Note that $E_{z} \max _{i}{ }^{\prime} i(\mu ; z), \max _{i} E_{z}{ }^{\prime} i(\mu ; z)$, and that $E_{z}{ }^{\prime} i(\mu ; z)=E_{w}\left(v_{i}(\mu ; w)\right)$. Since $\max _{i} E_{w}\left(v_{i}(\mu ; w)\right)$ is the expected et ciency associated with the auction when bidder $\mathrm{n}$ is absent, we obtain the desired result: for any realization $\mathrm{f} \mu_{1} ;: ; ; \mu_{h_{i}} \mathrm{~g}$ expected e \pm ciency is larger when bidder $\mathrm{n}$ is present than when he is absent.

\subsection{A dding an informed bidder to asymmetrically informed bidders}

We now illustrate how in asymmetric setting 2, the addition of an informed bidder may deteriorate (ex ante) et ciency.

We consider a situation with three bidders $\mathrm{i}=1 ; 2 ; 3$ and two characteristics $\mathrm{K}=$ $\mathrm{f} 1 ; 2 \mathrm{~g}$. We make the following assumption regarding the structure of the preference and information.

Assumption 1 Preferences: as in Example 2, with $K_{1}=K_{3}=K$ and $K_{2}=f 2 g$ : Information: $\mathrm{H}_{1}=\mathrm{flg}, \mathrm{H}_{2}=$; and $\mathrm{H}_{3}=\mathrm{K}$.

The information structure thus corresponds to that of asymmetric setting 2: Bidder 3 is fully informed of $w=f w^{1} ; w^{2} g$; Bidder 2 is totally uninformed. Bidder 1 is partially informed of $w$; he only knows $w^{1}$. 
The structure of preferences corresponds to the following:

$$
v_{i}(\mu ; w)=\begin{aligned}
& \vdots \mu+w^{1}+w^{2} \text { if i } 2 \text { f } 1 ; 3 g \\
& \mu+w^{2} \text { if } i=2
\end{aligned}
$$

A simple interpretation of this setup is as follows: $w^{2}$ represents a purely common value characteristic that applies to all bidders while $w^{1}$ represents a common characteristic that applies to bidders 1 and 3 only, for example because bidder 2 is known to use a technology di ßerent from that of bidders 1 and 3 .

Concerning the parameters $\mu$ and $w^{k}$, we make the following assumption.

Assumption 2: All variables $\mu, i=1 ; 2$, and $w^{1}, w^{2}$ are assumed to be drawn from independent distributions denoted by $f_{i}\left(\phi, i=1 ; 2\right.$ and $g_{k}(\phi, k=1 ; 2$, with supports $\left[\mu ; \mu^{k}\right], i=1 ; 2$ and $\left[\underline{w}^{k} ; \mathbb{W}^{k}\right], k=1 ; 2$, respectively. We assume that $\uplus_{3}=\mu_{3}^{1}=0, \Perp_{1}, 0$, and $w^{1}+w^{2}<\Perp_{2}$.

Note that A ssumption 2 implies that the informed bidder 3 is always less e \pm cient than bidders 1 and 2. We will analyze the equilibria in undominated strategies of the ascending price auction and obtain the following result:

Proposition 6 Under Assumptions 1 and 2, the presence of bidder 3 in the ascending price auction deteriorates expected e \pm ciency.

Proof. Consider ${ }^{-}$rst the situation without the informed bidder 3. The private information held by $i=1 ; 2$ is irrelevant for the determination of the valuation of bidder $\mathrm{j} \in \mathrm{i}, \mathrm{j} 2 \mathrm{fl} ; 2 \mathrm{~g}$. The auction can thus be analyzed as a private value ascending price auction: the most $e \pm$ cient bidder among $i=1 ; 2$ gets the object. ${ }^{21}$ Since $\mu_{1}>0$ and $\bar{\mu}_{3}=0$, the informed bidder 3 is always less etcient than bidder 1 , and therefore the ascending price auction without the informed bidder 3 allocates the good to the most ex cient bidder.

\footnotetext{
${ }^{21} T$ he strategy for bidder 1 (with private information $\left.\mu_{1} ; w^{1}\right)$ is to drop out at price $\mu_{1}+w^{1}+E\left(w^{2}\right)$ (if bidder 2 is still present). The strategy for bidder 2 (with private information $\mu_{2}$ ) is to drop out at price $\mu+E\left(w^{2}\right)$.
} 
Consider now the situation with all three bidders. It cannot allocate the good more e \pm ciently than the ascending price auction without the informed bidder 3 , since in the latter case the most $\mathrm{e} \pm$ cient allocation is obtained. We will prove that it does strictly worse, thus showing that the addition of the informed bidder 3 deteriorates expected e \pm ciency.

We ${ }^{-}$rst note that it is a (weakly) dominant strategy for bidder 3 with private information $\left(w^{1} ; w^{2}\right)$ to drop out (since $\left.\mu_{3}=0\right)$ at:

$$
b_{3}\left(w^{1} ; w^{2}\right)=w^{1}+w^{2}:
$$

It is therefore optimal for bidders 1 and 2 to wait for bidder 3 to drop out, since the value for bidders 1 and 2 is always (whatever the realizations of $\mu ; w^{i}$ ) larger than $b_{3}\left(w^{1} ; w^{2}\right)$ (this is because $\underline{\mu}_{1}>0$ and $\left.w^{1}<w^{1}+w^{2}<\mu_{2}\right)$

Let $b_{3}$ denote the price at which the informed bidder 3 drops out. At that price, there are two bidders left: bidders 1 and 2: From $b_{3}$, bidder 1 (with private information $\mu_{1}, w^{1}$ ) can perfectly infer the value of the object to him, i.e. it is worth $\mu \mathrm{l}+\mathrm{b}_{3}{ }^{22} \mathrm{He}$ will thus remain in the auction until the price reaches the level:

$$
b_{1}\left(\mu_{1} ; w^{1} ; b_{3}\right)=\mu_{1}+b_{3}:
$$

For the allocation to be e \pm cient bidder 2 would have to perfectly infer the value of the object in equilibrium (since bidder 1 does). We know ckeck however that bidder 2 (with private information $\mu_{2}$ ) can only imperfectly infer the value of the object in equilibrium. In equilibrium, she remains in the auction until the price reaches the level:

$$
b_{2}=\mu_{2}+E\left[w^{2} j w^{1}+w^{2}=b_{3} \text { and } b_{1}\left(\mu_{1} ; w^{1} ; b_{3}\right)=b_{2}\right]:
$$

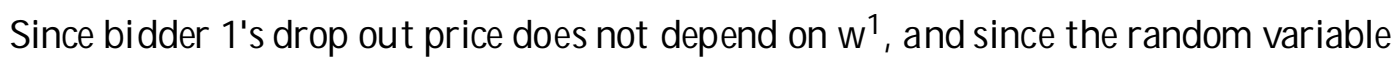
$\mu_{1} ; w^{1} ; w^{2}$ are independent, bidder 2 drops out at price:

$$
b_{2}\left(\mu_{2} ; b_{3}\right)=\mu_{2}+E\left[w^{2} j w^{1}+w^{2}=b_{3}\right] ;
$$

\footnotetext{
${ }^{22} \mathrm{~N}$ ote that the same conclusion would hold if bidder 1 knew $\mu_{1}$ only (and not $w^{1}$ ).
} 
which con $^{-}$rms that bidder 2 in equilibrium only imperfectly infers the value of $w^{2}$. Bidder 1 (resp. bidder 2) obtains the good whenever

$$
\mathrm{b}_{1}\left(\mu_{1} ; \mathrm{w}^{1} ; \mathrm{b}_{3}\right) \underset{(\text { resp: }<)}{>} \mathrm{b}_{2}\left(\mu_{2} ; \mathrm{b}_{3}\right) \text {; }
$$

and the allocation is ine \pm cient for example when:

$$
\mu_{2}+E\left[w^{2} j w^{1}+w^{2}=b_{3}\right]<\mu_{1}+w^{1}+w^{2}<\mu_{2}+w^{2}:
$$

\section{Comment 1:}

The induced allocation need not be e \pm cient because in equilibrium, the inferences made by bidder 1 and 2 about the value of the purely common value $w^{2}$ di Rer. As a result, both types of mistake may occur in equilibrium: the object may be allocated to bidder 1 although bidder 2 is more e \pm cient (this occurs when bidder 2 underestimates $\mathrm{w}^{2}$ ); and the object may be allocated to bidder 2 although bidder 1 is more e \pm cient (this occurs when bidder 2 overestimates $w^{2}$ ).

To illustrate this point, consider the case in which $w^{1}$ and $w^{2}$ are drawn independently from the same distribution. Then $E\left[w^{2} j w^{1}+w^{2}=b_{3}\right]=b_{3}=2$, and thus

$$
b_{2}\left(\mu_{2} ; b_{3}\right)=\mu_{2}+b_{3}=2:
$$

Bidder 1 (resp. bidder 2) gets the object whenever

$$
\mu_{\text {i }} \mu_{2} \underset{(\text { resp: }<)}{>} i \frac{w^{1}+w^{2}}{2} \text { : }
$$

On the other hand, bidder 1 is more (resp. less) e \pm cient than bidder 2 whenever

$$
\mu_{1} \text { i } \mu_{2} \underset{(\text { resp: }<)}{>} \text { i } w^{1}:
$$

Thus, whenever

$$
\mu_{1} \text { i } \mu_{2}>\text { i } \frac{w^{1}+w^{2}}{2} \text { and } \mu_{1} \text { i } \mu_{2}<\text { i }^{1}
$$

or

$$
\mu_{1} \text { i } \mu_{2}<\mathrm{i} \frac{\mathrm{w}^{1}+\mathrm{w}^{2}}{2} \text { and } \mu_{1} \mathrm{i} \mu_{2}>\mathrm{i} \mathrm{w}^{1}
$$


the good is allocated to the less e \pm cient bidder among $\mathrm{f} 1 ; 2 \mathrm{~g}$ resulting in an e \pm ciency loss of ${ }^{\overline{ }} \mu_{1}+w^{1} i \mu_{2}{ }^{\overline{ }}$ as compared with the situation in which bidder 3 is not present at the auction.

\section{Comment 2:}

If we consider the second price auction instead of the ascending price auction, the "nal allocation is ex post ex cient even when all three bidders are present at the auction. Thus, the second price auction performs better in this case than the ascending price auction when all three bidders are present. To see this, observe that in a second price auction, bidders 1 and 2 would bid:

$$
b_{1}\left(\mu_{1} ; w^{1}\right)=\mu_{1}+w^{1}+E w^{2} \text { and } b_{2}\left(\mu_{2}\right)=\mu_{2}+E w^{2} ;
$$

respectively (because the condition $w^{1}+w^{2}<\underline{H}_{2}$ implies that the informed bidder 3 cannot get the object in equilibrium). It follows that the ${ }^{-}$nal allocation is ex post etcient.

Comment 3:

The reason why the presence of the informed bidder deteriorates e \pm ciency in Proposition 6 is somewhat di ßerent from that in Proposition 2. Here, the ine \pm cient informed bidder never acquires the object. However, his mere presence modi ${ }^{-}$es the competition between bidders 1 and 2: It does so because the information conveyed by the strategy of the extra informed bidder is not the same for the two bidders $i=1 ; 2$ in equilibrium.

\subsection{Adding an uninformed bidder to informed bidders}

The negative erect of competition observed in subsections 4.1 and 4.2 is due to the fact that the bidding strategy of the uninformed or partially informed bidders is a rected by the presence of the extra informed bidder.

We now provide a class of situations (this is asymmetric setting 3 ) in which the presence of the extra bidder does not a eect the bidding strategies of the remaining bidders. For this class, the addition of the extra bidder enhances e \pm ciency. 
Consider the following setup. The common value element $w$ is known to bidders $\mathrm{i}=1 ;:: \mathrm{n}$ i 1 ; i.e. $\mathrm{H}_{\mathrm{i}}=\mathrm{K}$. Bidder $\mathrm{n}$ is uninformed of $\mathrm{w}$, i.e. $\mathrm{H}_{\mathrm{n}}=$; . The common value element $\mathrm{w}$ is distributed according to $\mathrm{g}(\phi$. As before, each bidder $\mathrm{i}$ knows his own private value element $\mu$, which is distributed according to $f_{i}(\phi$. Given $\mu$ and $w$, the value of the object to bidder $i$ is $v_{i}(\mu ; w)$ :

Proposition 7 The participation of bidder $n$ always raises e \pm ciency in second price or ascending price auctions.

Proof. Consider ${ }^{-}$rst the second price auction. All informed bidders bid according to $b_{i}(\mu ; w)=v_{i}(\mu ; w)$, and their bidding strategy is not a Rected by the participation of another bidder. Let $\bar{v}=\max _{i} \cdot n_{i} 1 V_{i}(\mu ; w)$, and let $\bar{f}$ denote the distribution over $\nabla$. W hen the entrant bidder bids $b_{n+1}$ and makes the highest bid, the second highest bid is equal to $\bar{v}$, hence his gain is equal to $v_{n}\left(\mu_{h} ; w\right)$ i $\bar{v}$. Thus his expected gain from bidding $b_{n}$ is equal to

$$
G\left(\mu_{h} ; b_{n}\right)={ }_{v \cdot b_{n}}^{Z}\left[v_{n}\left(\mu_{h} ; w\right) ; \nabla\right] \bar{f}(\nabla) g(w) d \nabla d w:
$$

For each realization $\mathrm{H}_{\mathrm{h}}$, the expected gain of the uninformed bidder thus coincides with the expected e \pm ciency change due to the presence of bidder $\mathrm{n}$ (note that the presence of bidder $\mathrm{n}$ does not change the allocation betwen the informed when in the event where bidder $n$ does not get the object). Since, in equilibrium, the bidding strategy $b_{n}\left(\mu_{h}\right)$ of the uninformed bidder satis ${ }^{-} e s$

$$
\mathrm{G}\left(\mu_{h} ; b_{n}\left(\mu_{h}\right)\right), 0 ;
$$

the participation of bidder $\mathrm{n}$ may only enhance et ciency.

The analysis of ascending price auction is similar. Instead of looking at each realization $\mu_{n}$, we consider the random variables $\mu_{n} ; v_{1} ;:: v_{n_{i}}$ and $i_{0}$ where $v_{i}=$ $v_{i}(\mu ; w)$; for $i=1 ; \ldots ; n i \quad 1$ and $i_{0}=\underset{i<n}{\arg \max } v_{i}$, and we consider the realizations $\mathrm{f} \mu_{h} ; f v_{i} g_{i \in i_{0}} g$. For each such realization, if bidder $n$ modi-es the ${ }^{-}$nal allocation, expected e \pm ciency must increase (by the same argument as above). 


\section{Conclusion}

This paper has shown that when bidders have multidimensional signals ( on a private, a common and possibly a partially common element), the addition of one bidder at the auction stage may deteriorate expected e \pm ciency in asymmetric cases in either the second price or the ascending price auction. One should thus be cautious when recommending to systematically promotethe maximum participation in procurement like auctions. ${ }^{23}$

Speci cally, our analysis suggests that the addition of a bidder who does not have (much) information a Recting the valuations of others is likely to be good for et ciency. Thus, our analysis gives little ground to restricting the access to auctions of entrant bidders.

Restricting the access of bidders who have some information (relevant to other bidders) may be justi ${ }^{-}$able in some cases, as our paper shows. A systematic analysis of access restriction deserves further research.

\section{Appendix}

Consider a setup in which bidder $\mathrm{i}$ has private information on $\mu_{\mathrm{i}}$ and $\mathrm{w}^{\mathrm{k}}, \mathrm{k} 2 \mathrm{H}_{\mathrm{i}}$. Denoting by

$$
w_{i}={ }_{k 2 H_{i}}^{x} w^{k} ;
$$

we assume that the private information $\left(\mu_{i} ; w_{i}\right)$ held by bidder $i$ is independently distributed from that of any other bidder $\mathrm{j}, \mathrm{j} \in \mathrm{i}$ (in particular, $\mathrm{H}_{\mathrm{i}} \backslash \mathrm{H}_{\mathrm{j}}=$; $8 \mathrm{i} ; \mathrm{j} \in \mathrm{i})$. Besides, for all $\mathrm{i}$ there exist draws of $\left(\mu ; w_{j}\right)_{j 2 \mathrm{~N}}$ such that bidder $\mathrm{i}$ is the most e \pm cient bidder. We have:

\footnotetext{
${ }^{23}$ A nother imp ortant reason for why more competition (or more participation) at the auction stage may not enhance e \pm ciency is that of market structure considerations (because then the valuation may include preemption or predatory arguments and give rise to war of attrition phenomena, see J ehiel and Moldovanu 1996).
} 
Proposition 8 There exists no sale mechanism and thus no auction format that allows to allocate the good to the ex post et cient bidder with probability 1 .

The technique of proof and argument is analog to that in J ehiel, M oldovanu and Stacchetti (1996) (see also J ehiel and Moldovanu (1998) and Dasgupta and Maskin (1998)) .

Proof. By the revelation principle there is no loss of generality in restricting attention to direct incentive mechanisms. Such a mechanism is de ned by the functions $\mathrm{p}\left(\phi ; \mathrm{y}_{\mathrm{i}}\left(\phi\right.\right.$ from $\mathrm{S}=\mathrm{S}_{\mathrm{i}} \notin \mathrm{S}_{\mathrm{i} i} !<$ where 1$) \mathrm{S}_{\mathrm{i}}=[\mu ; \bar{\mu}] \pm f_{\mathrm{k}_{2} \mathrm{H}_{\mathrm{i}}}\left[\mathrm{w}^{k} ; \overline{\mathrm{w}}^{k}\right]$ is the type space of each bidder, 2) $p_{i}\left(s_{i} ; s_{i} i\right)$ is the probability that the good is allocated to $\mathrm{i}$ when the reports of $\mathrm{i}$ and all other bidders $\mathrm{i} i$ are $\mathrm{s}_{\mathrm{i}}$ and $\mathrm{s}_{\mathrm{i}} \mathrm{i}$, respectively and 3) $y_{i}\left(s_{i} ; s_{i} i\right)$ is the payment made by bidder $i$ when the reports are $\left(s_{i} ; s_{i} i\right)$. It is convenient to de ${ }^{-}$ne

$$
y_{i}\left(t_{i}\right)=s_{s_{i}}^{z} x_{i}\left(t_{i} ; s_{i} i\right) h_{i i}\left(s_{i i}\right) d s_{i} i
$$

and

$$
q\left(t_{i}\right)={ }_{s_{i} i}^{z} p_{i}\left(t_{i} ; s_{i} i\right) h_{i ~ i ~}\left(s_{i} i\right) d s_{i} i
$$

as the expected payment made by $\mathrm{i}$ and expected probability that $\mathrm{i}$ gets the good respectively when i reports type $t_{i}$.

The expected utility that $i$ gets when his signal is $s_{i}$ and he reports $t_{i}$ while assuming that all other report truthfully is given by:

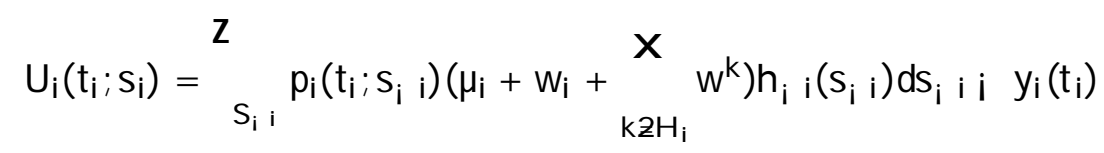

or after rearranging and making the change of variable $\left(\mu ; w_{i}\right)$ into $\left(z_{i} ; w_{i}\right)$ where $z_{i}=\mu+w_{i}:$

$$
U_{i}\left(t_{i} ; s_{i}\right)=q\left(t_{i}\right) z_{i}+{ }_{s_{i} i}^{z} p\left(t_{i} ; s_{i} i\right) \underbrace{x}_{k Z H_{i}} w^{k}) h_{i i}\left(s_{i} i\right) d s_{i} \text { i i } y_{i}\left(t_{i}\right):
$$

Let $\mathrm{V}_{\mathrm{i}}\left(\mathrm{s}_{\mathrm{i}}\right)=\mathrm{U}_{\mathrm{i}}\left(\mathrm{t}_{\mathrm{i}} ; \mathrm{s}_{\mathrm{i}}\right)$. If bidder $\mathrm{i}$ with type $\mathrm{s}_{\mathrm{i}}$ prefers announcing $\mathrm{t}_{\mathrm{i}}=\mathrm{s}_{\mathrm{i}}$ (incentive constraint) it must be that (assuming that $V_{i}\left(s_{i}\right)$ is locally di ®erentiable and using 
the envel ope theorem):

$$
\frac{@ \mathbb{V}_{i}\left(s_{i}\right)}{@ s_{i}}=\frac{@ b_{i}\left(t_{i} ; s_{i}\right)}{@ i_{i}} j_{t_{i}=s_{i}}=q\left(s_{i}\right)
$$

and

$$
\frac{@ V_{i}\left(s_{i}\right)}{@ N_{i}}=\frac{\left(\mathrm{d}_{i}\left(t_{i} ; s_{i}\right)\right.}{@ N_{i}} j_{t_{i}=s_{i}}=0
$$

By the C auchy-Schwartz identity $\left(\frac{\varrho^{2} V_{i}\left(s_{i}\right)}{\Phi_{i} @ V_{i}}=\frac{\Theta^{2} V_{i}\left(s_{j}\right)}{@ N_{i} @ z_{i}}\right)$, this implies that

$$
\frac{@_{i}\left(s_{i}\right)}{Q_{i}}=0 \text { : }
$$

Thus, to satisfy the incentive constraints, it should be that $q\left(s_{i}\right)$ is a sole function of $z_{i}=\mu+w_{i}$.

Consider the rule that allocates the good to the most $\mathrm{e} \pm$ cient bidder with probability 1. That rule leads to $q_{i}^{\text {ef } f}\left(s_{i}\right)=\operatorname{Prf} \mu_{i}>\mu_{j}$ for all $j \in$ ig, or after the change of variable:

$$
q^{e f f}\left(s_{i}\right)=\sum_{j \in i}^{1} F_{j}\left(Z_{i} i \quad w_{i}\right) \text {; }
$$

where $F_{j}\left(\phi\right.$ denoted the cumulative distribution of $f_{j}(\phi$. That function clearly depends on $w_{i}$ and therefore is not implementable whatever the mechanism to be considered.

\section{R eferences}

[1] Ausubel, L. (1997): An et cient ascending-bid auction for multiple objects," mimeo.

[2] B ulow, J . and Klemperer, P. (1996) \A uctions versus Negotiations", American E conomic Review, 86, 180-194

[3] B ulow, J . and K lemperer, P. (1998) "Prices and the Winner's Curse," mimeo $\mathrm{Nu} \pm$ eld College, Oxford.

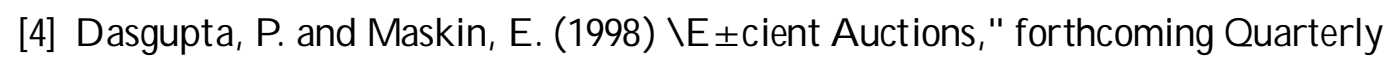
J ournal of Economics. 
[5] Gul, F . and A. Postlewaite (1992) "A symptotic E \pm ciency in L arge Exchange Economies with A symmetric Information" E conometrica 60, 1273-92.

[6] J ehiel, P. and B. Moldovanu (1996): Strategic Non-participation," Rand J ournal of Economics, Spring issue.

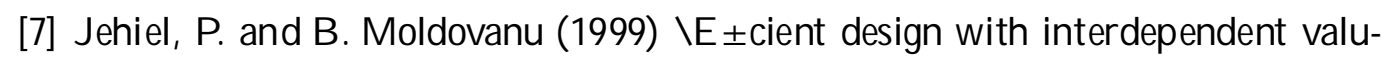
ations," mimeo.

[8] J ehiel, P., B. M oldovanu, and E. Stacchetti (1996) \How (not) to sell nuclear weapons," American Economic Review, September issue.

[9] Maskin, E. (1992): "Auctions and privatizations," in Privatization ed. by H. Siebert.

[10] M askin, E. and Riley (1999): "A symmetric auctions," forthcoming Review of E conomic Studies.

[11] M ilgrom, P. and Weber, (1982) \A theory of A uctions and Competitive Bidding', E conometrica, 50, 1089-1122

[12] Perry, M . and P. R eny (1999a): "On the failure of the linkage principle," E conometrica.

[13] Perry, M. and P. Reny (1999b): "An ex-post etcient auction," mimeo.

[14] Pesendorfer W. and Swinkels (1999): "E \pm ciency and I nformation A ggregation in Auctions," forthcoming American Economic Review. 